\title{
Redirecting host preexisting influenza A virus immunity for cancer immunotherapy
}

\author{
Bharat K. R. Chaganty ${ }^{1,2} \cdot$ Songbo Qiu ${ }^{1} \cdot$ Yang Lu$^{1} \cdot$ Gabriel Lopez-Berestein $^{1,2} \cdot$ Bulent Ozpolat $^{1,2} \cdot$ Zhen Fan $^{1,2}$ (1)
}

Received: 15 September 2021 / Accepted: 22 October 2021 / Published online: 3 November 2021

(c) The Author(s), under exclusive licence to Springer-Verlag GmbH Germany, part of Springer Nature 2021

\begin{abstract}
We tested the concept that host preexisting influenza A virus immunity can be redirected to inhibit tumor growth and metastasis through systemic administration of influenza A virus-related peptides to targeted tumors. Mice infected with influenza A virus strain A/Puerto Rico/8/34 (PR8) were used as a model of a host with preexisting viral immunity. The extent to which preexisting influenza A immunity in PR8-immunized mice can be redirected to inhibit tumor growth and metastasis was first examined by ectopic expression of influenza A nucleoprotein (NP) and hemagglutinin (HA) in syngeneic mammary tumor cells via lentiviral transduction. Then, the feasibility of implementing this strategy using a systemic therapy approach was assessed by systemic delivery of major histocompatibility complex class I (MHC-I)-compatible peptides to targeted mammary tumors overexpressing human epidermal growth factor receptor-2 (HER2) in mice using a novel HER2-targeting single-lipid nanoparticle (SLNP). Our results show that preexisting influenza A immunity in PR8-immunized mice could be quickly redirected to syngeneic tumors expressing influenza A NP and HA, leading to strong inhibition of tumor growth and metastasis and improvement of survival compared to the findings in antigen-naïve control mice. MHC-I-compatible peptides could be delivered to targeted mammary tumors in mice using the HER2-targeting SLNP for antigen presentation, which subsequently redirected preexisting influenza A immunity to the tumors to exert antitumor activities. In conclusion, preexisting influenza A immunity can be repurposed for cancer immunotherapy through systemic delivery of influenza Arelated peptides to targeted tumors. Further development of the strategy for clinical translation is warranted.
\end{abstract}

Keywords Influenza A virus $\cdot$ Preexisting immunity $\cdot$ Human epidermal growth factor receptor- $2 \cdot$ Single-lipid nanoparticle $\cdot$ Cancer immunotherapy

$\begin{array}{ll}\begin{array}{l}\text { Abbreviations } \\ \text { DOPC }\end{array} & \begin{array}{l}\text { 1,2-Dioleoyl-sn-glycero-3-phosphati- } \\ \text { dylcholine }\end{array} \\ \text { FACS } & \begin{array}{l}\text { Fluorescence-activated cell sorting } \\ \text { Hemagglutinin }\end{array} \\ \text { HER2 } & \begin{array}{l}\text { Human epidermal growth factor } \\ \text { receptor-2 } \\ \text { Major histocompatibility complex } \\ \text { class I }\end{array} \\ \text { MHC-I } & \begin{array}{l}\text { Membrane-binding } \\ \text { Nucleoprotein }\end{array} \\ \text { MB } & \end{array}$

Zhen Fan

zfan@mdanderson.org

1 Department of Experimental Therapeutics, The University of Texas MD Anderson Cancer Center, Unit 1950, 1515 Holcombe Boulevard, Houston, TX 77030, USA

2 MD Anderson Cancer Center UTHealth Graduate School of Biomedical Sciences, Houston, TX 77030, USA
PR8

SLNP

TZM-MB

TZM-MB-SLNPs HER2-targeting SLNPs

\section{Introduction}

The use of vaccines to eliminate infectious diseases, including some caused by the most deadly pathogens, is one of the greatest achievements in human history [1]. However, the dream of using vaccines to prevent or treat human cancer remains largely unfulfilled [2,3], except in a few types of human cancer that have a clear viral origin, e.g., cervical cancer, which is etiologically linked to human papillomavirus infection [4]. Although tumor-specific cytotoxic T cells have been observed in cancer patients, most tumor-associated antigens investigated so far are self-proteins or mutated 
self-proteins that are unable to elicit immune responses comparable in strength to immune responses to exogenous antigens of viral origin [5]. Moreover, cancer cells reside in a formidably immunosuppressive tumor microenvironment wherein cytotoxic $\mathrm{T}$ cells directed against tumor-associated antigens are typically suppressed [6]. Recent promising clinical responses to immune checkpoint blockade therapy in patients with several types of cancer represent a milestone in the history of cancer immunotherapy; however, significant challenges remain because the degree of clinical response to immune checkpoint blockade therapy varies substantially by cancer type and patient [7].

In contrast to the weak antitumor immune responses in the tumor microenvironment, cancer patients' preexisting immunity generated in response to previous infection or vaccination against infectious agents during childhood may remain functional in the form of memory $\mathrm{T}$ cells [8], which could be leveraged for cancer treatment. This notion is supported by studies of treatment of bladder cancer via intravesical instillation of bacillus Calmette-Guérin (BCG) [9]. Intravesical BCG instillation typically achieves response rates of $50 \%$ to $70 \%$ in patients with superficial non-muscle-invasive bladder cancer [10]. This treatment has long been believed to cause nonspecific stimulation of the tumor immune response through triggering local inflammation, an interpretation supported by William Coley's pioneering work [11]. In 2012, it was reported that intravesical instillation of BCG achieved 5-year recurrence-free survival rates of approximately $75 \%$ in patients who had received BCG vaccine in childhood versus $40 \%$ in patients who had not [9]. The researchers demonstrated in an animal model that delivery of BCG vaccine to the inner lining of the bladder via a urinary catheter, which rendered bladder cancer cells accessible to BCG-related antigens and presentation of the antigens in major histocompatibility complex class I (MHC-I), resulted in redirection of preexisting CD8 + T cells to the bladder cancer cells and triggered an immune response to the cancer cells [9]. However, most primary and metastatic tumors are not accessible for direct intratumoral injection or other local administration of vaccine-related antigens. An earlier study that established this concept was performed mainly with local delivery of recombinant viruses or vaccine-related antigens and examined only impacts on local tumor growth [12].

In the work described in this paper, we explored the feasibility of redirecting preexisting antiviral immunity acquired through vaccination or infection to cancer cells as a novel cancer immunotherapy, especially for metastatic cancer, through systemic delivery of virus-related antigens. We chose influenza as the model of viral infection because influenza immunity is common in the general population as millions of people around the world are infected with influenza every year and influenza vaccines are administered annually. Moreover, intratumoral injection of seasonal influenza vaccine has been reported to convert immunologically "cold" tumors to "hot" tumors [13]. Furthermore, it was recently reported that preexisting influenza virus-specific $\mathrm{T}$ cells could extend their surveillance to tumors after injection of adjuvant-free influenza-related peptides into mouse and human tumors [14]. Our hypothesis was that the immune system can be "tricked" to perceive cancer cells as influenza virus-infected cells following systemic delivery of virusrelated antigens to targeted tumors and consequently launch an effective immune response against the cancer cells for treatment of metastatic disease. To test our hypothesis, we used influenza A virus-related antigens because influenza A virus is the most common cause of influenza virus infection in humans $[15,16]$.

\section{Materials and methods}

\section{Mice and mouse tumor models}

BALB/c and C57BL/6 mice (6-8 weeks old) were purchased from Charles River Laboratories. All murine experiments were performed in accordance with the guidelines and protocols approved by the Institutional Animal Care and Use Committee at MD Anderson Cancer Center.

TUBO mouse mammary tumor cells, originally derived from a spontaneous mammary tumor of a rodent HER2neu transgenic mouse model $[17,18]$, were provided by Dr. Guido Forni (University of Turin, Orbassano, Italy). TUBO cells were transduced for expression of influenza A nucleoprotein (NP) [19] using the pLEX lentiviral transduction system (Thermo Fisher Scientific, Waltham, MA). The 4T1 and EO771 mouse mammary tumor cells, provided by Dr. Mien-Chie Hung (MD Anderson Cancer Center), were transduced for expression of NP, hemagglutinin (HA) [20, 21], NP plus HA, luciferase, or HER2 using the pLEX lentiviral transduction system. The plasmid DNA templates containing coding sequences of influenza A NP and HA were purchased from Sino Biological (Beijing, China). All mouse cell lines were grown in RPMI-1640 medium supplemented with $10 \%$ fetal bovine serum, $2 \mathrm{mM}$ glutamine, $100 \mathrm{U} / \mathrm{mL}$ penicillin, and $100 \mu \mathrm{g} / \mathrm{mL}$ streptomycin.

Mouse mammary tumors were established by implanting tumor cells in the mouse mammary fat pad. Growth of tumors in the mouse mammary fat pad was measured two-dimensionally twice a week using digital calipers, and tumor volumes were determined by using the formula: tumor volume $=(\pi / 6) \times$ length $\mathrm{x}$ width ${ }^{2}$, where length represents the longest tumor diameter and width represents the perpendicular short tumor diameter. Metastasis of luciferasetagged tumors was assessed with the IVIS Spectrum in vivo imaging system (Caliper Life Sciences, Hopkinton, MA) in 
living animals after intraperitoneal injection of D-luciferin (3.3 $\mathrm{mg}$ in $100 \mu \mathrm{L}$ ) and induction of anesthesia by inhalation of $2.5 \%$ isoflurane (IsoSol; Vedco, Inc., St. Joseph, MO). Bioluminescent imaging data were analyzed using Living Image software (Caliper Life Sciences).

\section{Immunization of mice with influenza A virus}

Preexisting influenza A virus immunity was primed by intranasal infection of BALB/c mice with A/Puerto Rico/8/34 (PR8, Avian Vaccine Services of Charles River Laboratories, Norwich, CT), a well-characterized H1N1 influenza A virus strain $[22,23]$, at a dose of $20 \mathrm{HA}$ units per $20 \mu \mathrm{L}$ of PBS. After infection, the mice were rested for 30 days to allow for clearance of the influenza virus and for development of adaptive immune responses. To boost immune response, the mice were subjected to a second dose of 60 HA units of PR 8 virus intranasally 10 days before tumor challenge.

\section{Quantification of IFN- $\gamma$ by enzyme-linked immunoassay (ELISA)}

Mouse IFN- $\gamma$ produced in conditioned medium following co-culture of mouse splenocytes and tumor cells was analyzed using a mouse IFN- $\gamma$ ELISA kit purchased from BD Biosciences (San Jose, CA). The ELISA procedure was performed in a 96-well microplate according to the protocol provided by the vendor. A $100 \mu \mathrm{L}$ of conditioned medium (diluted if necessary) from the co-culture was added to the wells of the 96-well microplate for IFN- $\gamma$ quantification.

\section{Immunophenotyping by multicolor fluorescence-activated cell sorting (FACS)}

Mouse tumors, tumor-draining lymph nodes, and spleens were processed by mincing the tissues into small pieces in a $70-\mu \mathrm{m}$ mesh cell strainer using a syringe plunger and then passing the samples through the strainer to isolate a single cell suspension in FACS buffer (0.5\% BSA in PBS). Single cell suspensions $\left(0.5-1 \times 10^{6}\right.$ cells/sample) were prepared in $100 \mu \mathrm{L}$ of FACS buffer and stained with various fluorescently conjugated primary antibodies along with an isotypematched control antibody for $30 \mathrm{~min}$ at $4{ }^{\circ} \mathrm{C}$, following $\mathrm{Fc}$ receptor blockade using $2.4 \mathrm{G} 2$ antibody. The cell samples were then washed twice with FACS buffer, and the intensity of fluorescence was measured by using a BD Biosciences Canto II analyzer. The data were analyzed by using FlowJo software.

Fluorescently conjugated primary antibodies used in the study were purchased from Tonbo Biosciences (San Diego, CA) or from BioLegend (San Diego, CA). The following antibodies were from Tonbo Biosciences:
PE-Cy7-anti-mouse CD3e (clone 145-2C11), APC-antimouse CD62L (L-Selectin) (MEL-14), Violet Fluor 450-anti-human/mouse CD44 (IM7), APC-anti-mouse FoxP3 (3G3), FITC-anti-mouse CD4 (RM4-5), PE-antimouse CD8a (53-6.7), PE-anti-mouse CD11c (N418), FITC-anti-mouse Ly-6G (Gr-1) (RB6-8C5), FITC-ratanti-mouse $\mathrm{IgG} 2 \mathrm{a}$ isotype control (2A3), and rat antimouse CD16/CD32 (2.4G2) antibodies. The following antibodies were from BioLegend: Pacific Blue-anti-mouse CD49b (DX5) (pan-NK cells), BV421-anti-HER2 (24D2), and PE-Cy7-anti-mouse H-2K ${ }^{\mathrm{b}} /$ SIINFEKL (25-D1.16) antibodies.

\section{Generation of nanoparticles and injection of nanoparticles for HER2-targeted delivery of cargos to tumors in vivo}

Anti-human epidermal growth factor receptor-2 (HER2) trastuzumab was used to develop a novel single-lipid nanoparticle (SLNP) targeting HER2-overexpressing tumors. DNAs coding for trastuzumab heavy chain and light chain were synthesized according to the sequences at GenBank (GM685463.1 for trastuzumab heavy chain and GM685465.1 for trastuzumab light chain). The DNA sequence of a membrane-binding (MB) domain of membrane-bound $\mathrm{IgG}$, including a short sequence of extracellular domain and the transmembrane region with an intracellular cytoplasmic tail, was obtained from GenBank (BAC87509.1) and was fused to trastuzumab heavy chain at the 3' end via PCR. The PCR product and the DNA sequence for trastuzumab light chain were subcloned into a pLEX-based lentiviral construct and then transduced into CHO-S cells via lentiviral transduction. CHO-S cells were lysed using a mild lysis buffer (50 mM TrisHCl, pH 7.4, $150 \mathrm{mM} \mathrm{NaCl}, 1 \%$ Igepal CA-630, $1 \mathrm{mM}$ EGTA, $1 \mathrm{mM}$ EDTA, and a protease inhibitor cocktail [Sigma-Aldrich]). Trastuzumab fused with IgG MB domain (TZM-MB) was purified via binding to a protein A column, followed by elution with $0.1 \mathrm{M}$ glycine ( $\mathrm{pH} 2.6$ ), neutralization immediately with $1 \mathrm{M}$ TrisHCl, $\mathrm{pH} 11$, and dialysis against PBS (pH 6.7).

TZM-MB was used to prepare HER2-targeting SLNPs (TZM-MB-SLNPs) by addition of TZM-MB to a mixture of 1,2-dioleoyl-sn-glycero-3-phosphatidylcholine (DOPC) and the cargos (peptides). In brief, TZM-MB-SLNPs or SLNPs were prepared by mixing $2.5 \mu \mathrm{g}$ of cargo (peptides) with DOPC at a ratio of $1: 10(\mathrm{w} / \mathrm{w})$. Tween 20 was added to the mixture at a ratio of 1:19 (Tween 20:DOPC) [24, 25]. The mixture was vortexed, frozen in an acetone/dry ice bath, and lyophilized. This preparation was then hydrated with PBS incorporating $5 \mu \mathrm{g}$ of TZM-MB, trastuzumab (to make a simple mixture of trastuzumab with SLNPs to serve as a control), or PBS only and injected into mouse tail veins (100 $\mu \mathrm{L}$ per injection). 
To assess antigen presentation in the targeted tumor after delivery of TZM-MB-SLNPs in vivo, $\mathrm{H}-2 \mathrm{~K}^{\mathrm{b}}$-compatible ovalbumin peptide (SIINFEKL, InvivoGen, San Diego, CA) was used as the peptide cargo. To assess the therapeutic impact on tumor growth of systemic delivery of influenza A-related peptides encapsulated in TZM-MB-SLNPs to mice with preexisting influenza A immunity, 2 customsynthesized $\mathrm{H}-2 \mathrm{~K}^{\mathrm{d}}$-compatible influenza A peptides (RS Synthesis, Louisville, KY), one NP-related peptide (TYQRTRALV) and one HA-related peptide (IYSTVASSL), were used as the peptide cargo.

\section{Statistical analysis}

For analysis of data from in vivo and ex vivo experiments, the mean values with standard error of the mean or with standard deviation of the mean are presented. Differences between 2 groups were analyzed by using 2-tailed unpaired
Student's t test, whereas differences between multiple groups were analyzed by using 2 -way ANOVA. $p<0.05$ was considered statistically significant for all analyses.

\section{Results}

\section{Antitumor response to tumors expressing influenza A virus antigens is expeditious and more powerful in PR8-immunized mice than in antigen-naïve control mice}

We first optimized an influenza A virus infection/immunization protocol (Fig. 1A) by subjecting BALB/c mice to nasal dropping of PR8 virus at various doses ranging from 5 to $40 \mathrm{HA}$ units per $20 \mu \mathrm{L}$; a dose of $20 \mathrm{HA}$ units per $20 \mu \mathrm{L}$ was found to be the highest tolerable dose. On day 30 after immunization with PR8 virus or with an equal

A

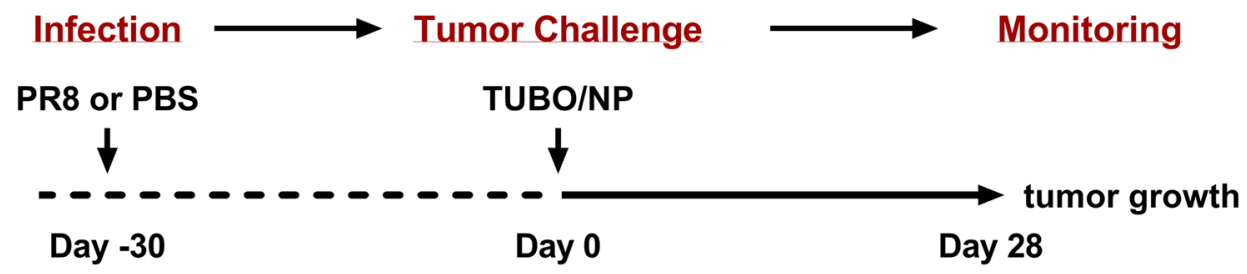

B

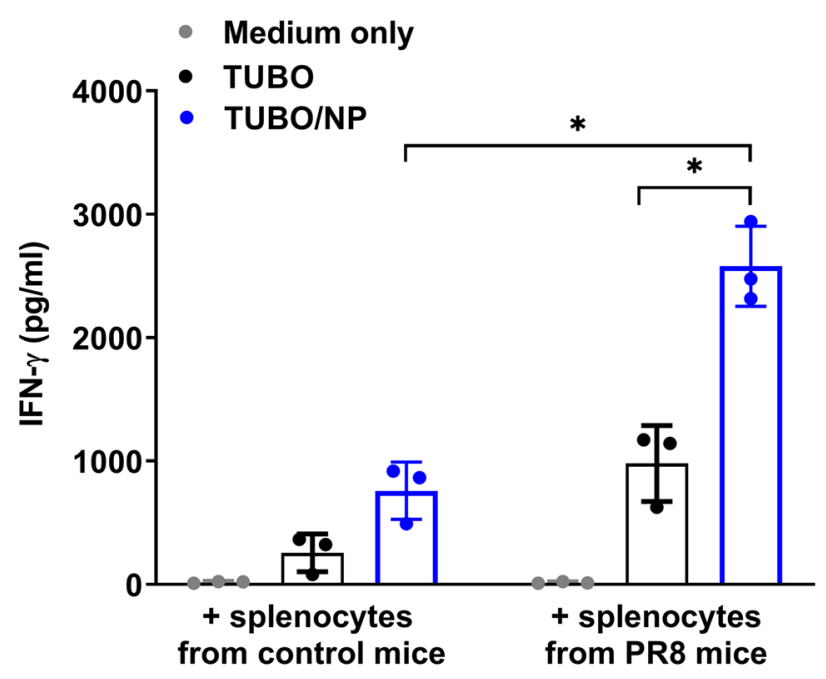

Fig. 1 Preexisting influenza A immunity in PR8-immunized mice can be redirected to inhibit growth of syngeneic TUBO mouse mammary tumors expressing influenza A virus NP protein. A Schematic illustration of PR8 immunization protocol in BALB/c mice (6-8 weeks old). B On day 30 after immunization with PR8 influenza A virus or mock immunization with PBS (control), 3 mice from each group were euthanized, and splenocytes were isolated, plated in 96-well microplates $\left(1 \times 10^{6}\right.$ cells/well), and co-cultured with TUBO or TUBO/NP cells

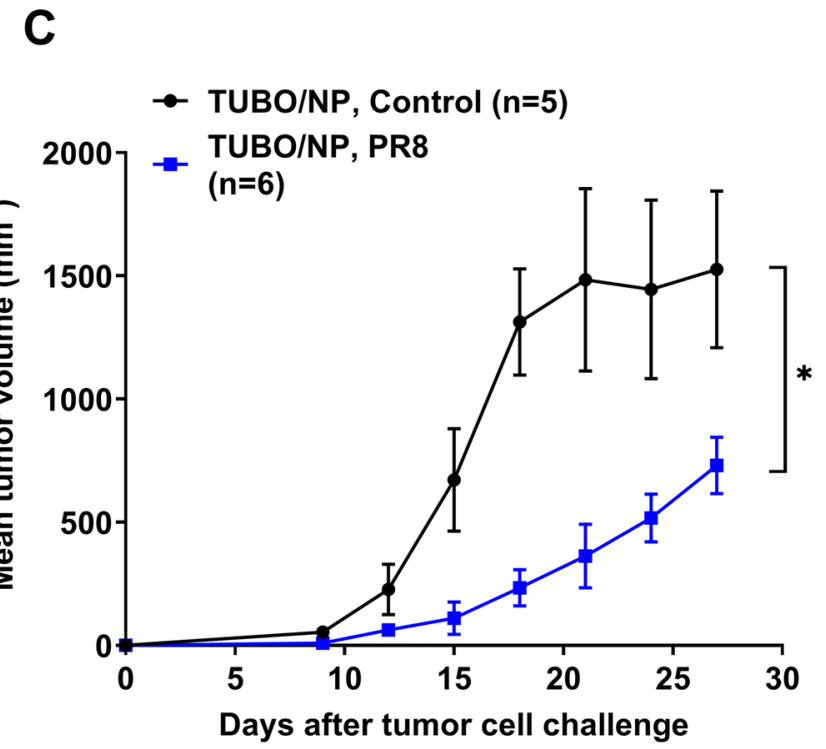

$\left(1 \times 10^{4}\right.$ cells/well) for $72 \mathrm{~h}$. Supernatants $(100 \mu \mathrm{L} / \mathrm{sample})$ were collected, and IFN- $\gamma$ production was quantified by ELISA. (C) On day 30 after immunization with PR8 influenza A virus or mock immunization with PBS, the remaining mice in the control group $(n=5)$ and the PR8 group $(n=6)$ were challenged with $2.5 \times 10^{6}$ TUBO/NP cells. Tumor volume was monitored twice weekly over the following 28 days. Data are presented as mean \pm standard error of the mean. * $p<0.05$ compared to corresponding control 
volume of PBS as a mock immunization, splenocytes from the mice in both groups were harvested and subjected to co-culture for $72 \mathrm{~h}$ with parental TUBO cells or TUBO cells transduced to express influenza A NP protein (termed TUBO/NP). As shown in Fig. 1B, following co-culture, the level of IFN- $\gamma$, a major cytokine released following $\mathrm{T}$ cell activation, was significantly higher in the conditioned medium from co-culture of TUBO/NP cells with splenocytes from PR8-immunized mice than in the conditioned medium from co-culture of TUBO/NP cells with splenocytes from antigen-naïve control mice. This result indicates that PR8-immunized mice had developed preexisting anti-influenza A immunity and thus responded to a recall antigen faster than the antigen-naïve control mice did. As shown in Fig. 1C, TUBO/NP tumors in the control mice grew robustly before the growth plateaued approximately 21 days after tumor cell implantation in the mammary fat pad, whereas TUBO/NP tumors in the PR8immunized mice grew significantly more slowly during the first 2 weeks after tumor cell implantation, a time interval before the mice could launch a priming immune response to NP. This finding supports the interpretation that the preexisting influenza A immunity in PR8-immunized mice was quickly recalled and redirected to TUBO/NP tumors to curb their growth.

We next sought to determine the extent to which the spread of cancer metastasis can be curbed by preexisting influenza A immunity in a similar scenario. Unlike TUBO cells, 4T1 mouse mammary tumor cells can metastasize spontaneously to multiple remote organs after being implanted in the mammary fat pad in BALB/c mice, and the metastasis can kill the mice [26]. The extent of metastasis of 4T1 tumor can be tracked by in vivo imaging of $4 \mathrm{~T} 1$ cells transduced to express a luciferase reporter (termed 4T1/Luc). We transduced 4T1/Luc cells to express influenza A-related antigens. In a pilot study, we found that expression of influenza A NP in 4T1 cells (to create cells termed 4T1/ Luc-NP) was insufficient to curb the metastasis of 4T1/Luc cells in PR8-immunized mice (data not shown). We therefore introduced a second influenza A protein, HA, in 4T1/ Luc-NP cells to create cells termed 4T1/Luc-NP/HA. We also gave the mice an additional boost of $60 \mathrm{HA}$ units of PR8 virus 30 days after priming immunization with $20 \mathrm{HA}$ units of PR8 virus and 10 days before the mice were challenged with $4 \mathrm{~T} 1 / \mathrm{Luc}$ or $4 \mathrm{~T} 1 / \mathrm{Luc}-\mathrm{NP} / \mathrm{HA}$ cells (Fig. 2A).

Figure $2 \mathrm{~B}$ shows the results of in vivo imaging on day 12 and day 33 after tumor cell challenge in PR8-immunized mice and in antigen-naïve control mice. In the 4T1/Luc group, tumors were detectable by in vivo imaging and palpable on day 12 after tumor cell implantation in both control and PR8immunized mice and grew aggressively afterward; by day 33 , metastasis was evident in both control and PR8-immunized mice (Fig. 2B, left 2 columns). 4T1/Luc tumors grew rapidly in both control and PR8-immunized mice (Fig. 2C), and by day 55, all these mice were dead (Fig. 2D). In contrast, in the 4T1/Luc-NP/HA group, tumors exhibited delayed growth in both control and PR8-immunized mice, which was expected because of combined strong immunogenicity of HA and NP antigens in $\mathrm{BALB} / \mathrm{c}$ mice. However, the growth delay was more pronounced in the PR8-immunized mice than in the control mice (Fig. 2B, right 2 columns). On day 12, in vivo imaging detected obvious 4T1/Luc-NP/HA tumor in 6 of 10 mice in the control group, compared to 1 of 10 mice in the PR8-immunized group; on day 33 , in vivo imaging detected obvious tumors in 7 of 10 mice in the control group, compared to 3 of 10 mice in the PR8-immunized group (Fig. 2B). The growth of 4T1/Luc-NP/HA tumors was significantly slower in the PR8-immunized mice than in the control group (Fig. 2C). At day 70, among the mice challenged with 4T1/Luc-NP/ HA cells, 7 of 10 mice in the control group had died, and the remaining 3 mice were alive and tumor free, whereas in the PR8-immunized group, remarkably, 7 of 10 mice were alive and tumor free (Fig. 2D). All surviving mice were monitored for 180 days after 4T1/Luc-NP/HA cell implantation, during which time there was no relapse of tumor growth, leading to a survival benefit (Fig. 2D).

Next, we assessed the extent to which the memory of influenza A immunity can be recalled to reject tumors expressing influenza $\mathrm{A}$ antigens in aged mice. We immunized BALB/c mice with PR8 virus at the age of 6 weeks. The PR8-immunized mice were kept in a pathogen-free facility, along with age-matched mice mock immunized with PBS, for 18 months, a time period roughly analogous to the time period of progression from birth to elderly age in humans. The PR8-immunized mice were given a PR8 virus boost 10 days before being challenged with 4T1/Luc-NP/HA cells, and the age-matched control mice received PBS only (Fig. 3A). The growth of 4T1/ Luc-NP/HA tumors in the age-matched control mice was slightly slower than the growth of 4T1/Luc tumors in the agematched control mice, but this difference was not statistically significant (Fig. 3B). In contrast, the growth of 4T1/Luc-NP/ HA tumors in the PR8-immunized/PR8-boosted mice was significantly slower than the growth of 4T1/Luc and 4T1/Luc-NP/ HA tumors in the age-matched control mice.

Together, the data in Fig. 1 through Fig. 3 support the notion that preexisting influenza A virus immunity can be quickly recalled and redirected to curb metastasis of tumors expressing influenza A-related antigens, which can lead to a survival benefit in PR8-immunized mice compared with the survival in antigen-naïve control mice, and that the preexisting influenza A immunity in PR8-immunized mice is longlasting and can be recalled upon a boost dose of PR8 virus. 
A

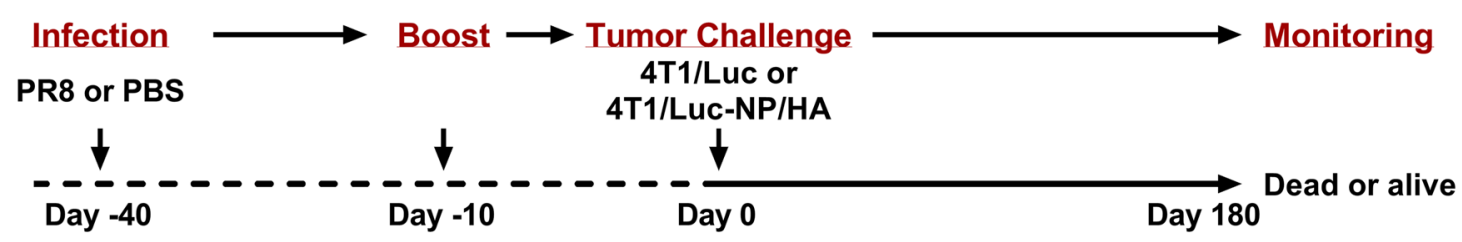

B
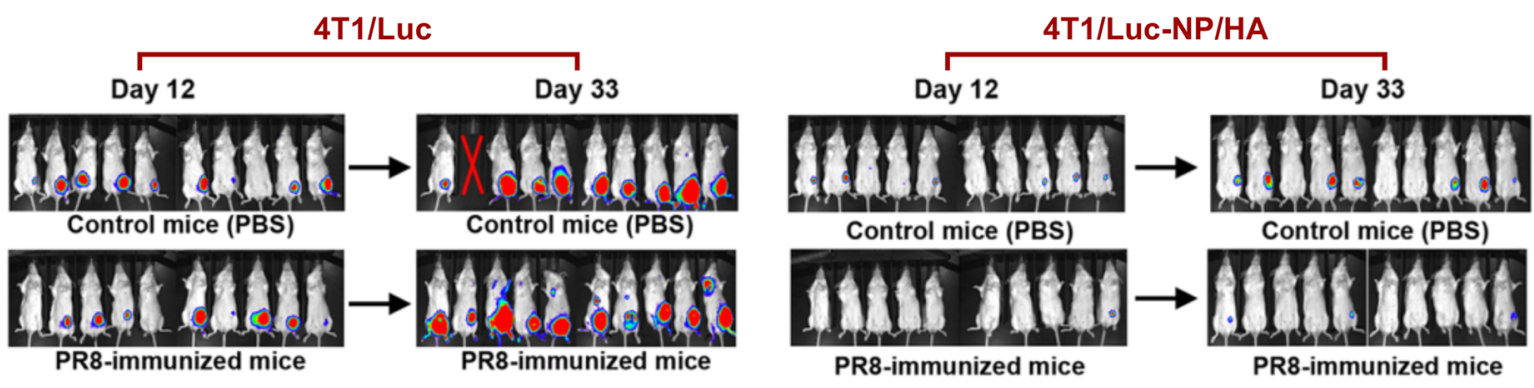

C
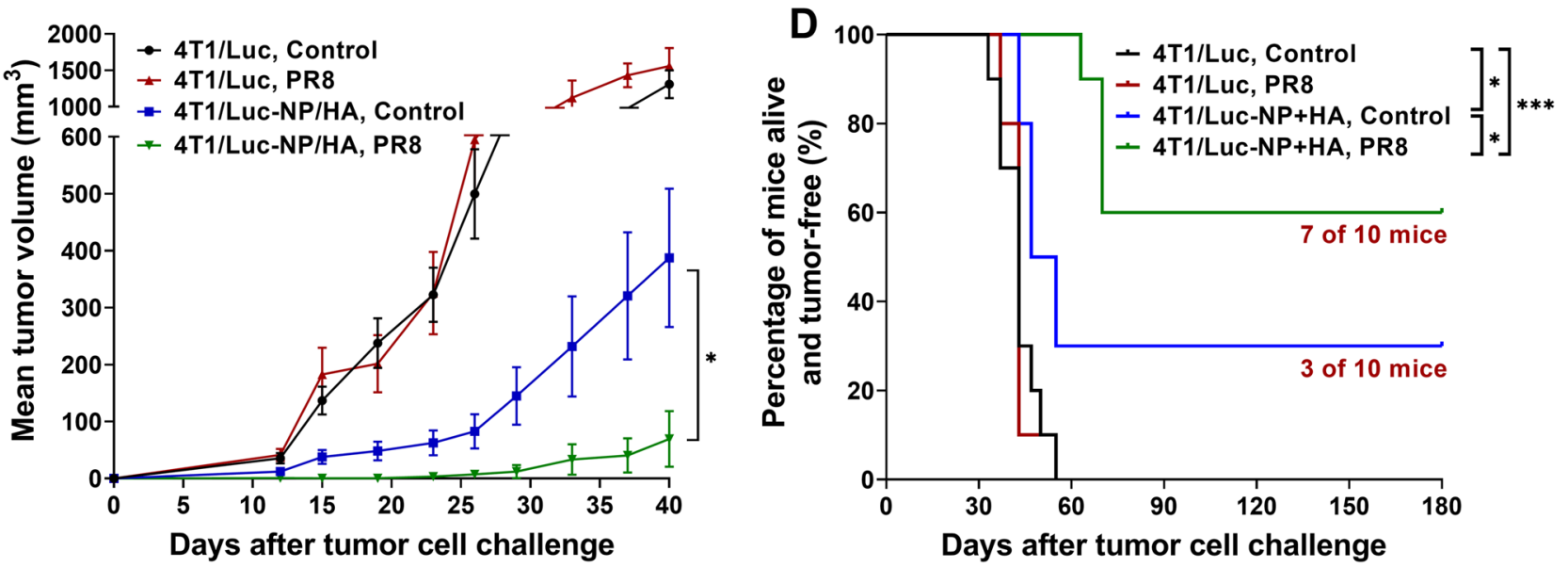

Fig. 2 Preexisting influenza A immunity in PR8-immunized mice can be redirected to inhibit metastasis of aggressive $4 \mathrm{~T} 1$ mouse mammary tumors expressing influenza A virus NP and HA proteins and prolong survival. A Schematic illustration of experimental procedure. BALB/c mice (6-8 weeks old) were immunized with $20 \mathrm{HA}$ units of PR8 influenza A virus or mock immunized with PBS (control) 40 days before and given a boost dose 10 days before tumor cell challenge, which was followed by monitoring as illustrated. B PR8-immunized and control mice (10 per group) were challenged

\section{Innate and adaptive immune responses to tumors expressing influenza $A$ virus antigens are stronger in PR8-immunized mice than in antigen-naïve control mice}

We analyzed the profiles of innate and adaptive immune cells in tumors and tumor-draining lymph nodes harvested from young PR8-immunized and control BALB/c mice 7 days after implantation of $4 \mathrm{~T} 1 / \mathrm{Luc}$ cells or $4 \mathrm{~T} 1 / \mathrm{Luc}-\mathrm{NP} / \mathrm{HA}$ cells. As shown in Fig. 4A, there were no significant differences in the percentages of total tumor-associated macrophages $\left(\mathrm{CD} 45^{+} \mathrm{CD} 11 \mathrm{c}^{-} \mathrm{CD} 11 \mathrm{~b}^{+} \mathrm{F} 4 / 80^{+}\right.$; Fig. $4 \mathrm{~A}$, left panel) or $\mathrm{M} 1$ macrophages $\left(\mathrm{CD} 45^{+} \mathrm{CD} 11 \mathrm{c}^{-} \mathrm{CD} 11 \mathrm{~b}^{+} \mathrm{F} 4 / 80^{+} \mathrm{CD} 86^{+}\right.$; Fig. 4A, right panel) between the tumors from

with $10^{6} 4 \mathrm{~T} 1 / \mathrm{Luc}$ or $4 \mathrm{~T} 1 / \mathrm{Luc}-\mathrm{NP} / \mathrm{HA}$ cells in the mammary fat pad and monitored for tumor growth and metastasis by in vivo imaging on day 12 and day 33 after tumor cell challenge. A red cross indicates that the mouse died before day 33. C Tumor volumes measured using calipers. Tumor volume measurement was discontinued after day 40 , when most of the mice challenged with 4T1/Luc cells had died. Data are presented as mean \pm standard error of the mean. D Survival curves. The surviving mice were closely monitored for up to 180 days. $* p<0.05 . * * * p<0.001$

PR8-immunized mice and control mice implanted with 4T1/Luc cells or $4 \mathrm{~T} 1 / \mathrm{Luc}-\mathrm{NP} / \mathrm{HA}$ cells. The percentages of total dendritic cells $\left(\mathrm{CD} 45^{+} \mathrm{CD} 11 \mathrm{c}^{+}\right.$; Fig. 4B, left panel) and their mature form $\left(\mathrm{CD} 45^{+} \mathrm{CD} 11 \mathrm{c}^{+} \mathrm{CD} 11 \mathrm{~b}^{-} \mathrm{CD} 86^{+}\right.$; Fig. 4B, right panel) were both higher in the tumors from PR8-immunized mice than in the tumors from control mice among the mice implanted with 4T1/Luc-NP/HA cells but not among the mice implanted with $4 \mathrm{~T} 1 / \mathrm{Luc}$ cells. The percentage of NK cells $\left(\mathrm{CD} 45^{+} \mathrm{CD} 3^{-} \mathrm{CD} 49 \mathrm{~b}^{+}\right)$was higher (Fig. 4C) and the percentage of myeloid-derived suppressor cells $\left(\mathrm{CD} 11 \mathrm{~b}^{+}\right.$Ly6G/Gr- $\left.{ }^{+}\right)$was lower (Fig. 4D) in PR8-immunized mice than in control mice among the mice implanted with 4T1/Luc-NP/HA cells but again not among the mice implanted with $4 \mathrm{~T} 1 / \mathrm{Luc}$ cells. These findings 
A

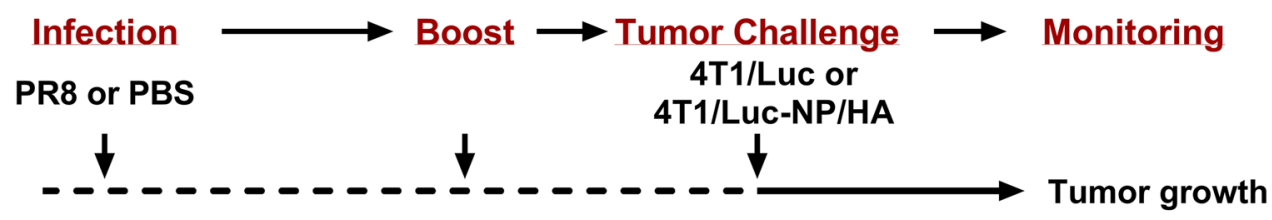

Day -540

Day -10

Day 0

Day 38

(18 months)

B

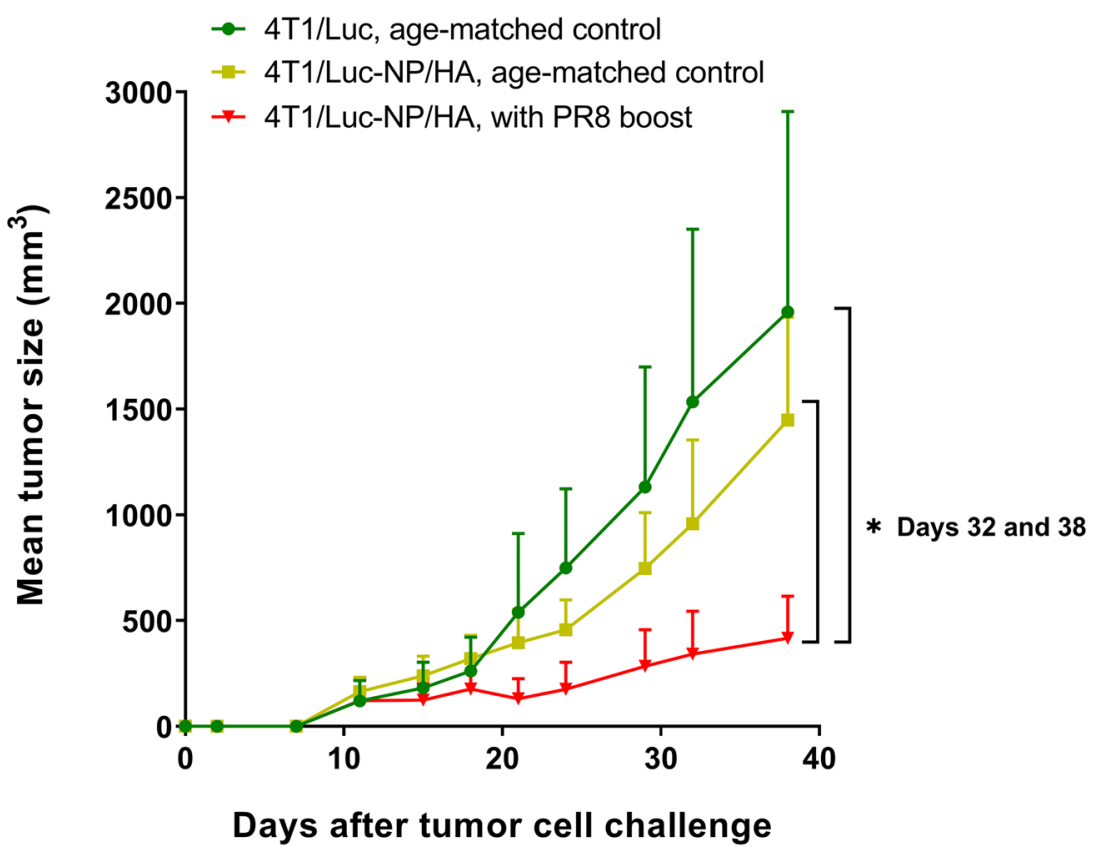

Fig. 3 Influenza A immunity in elderly PR8-immunized mice can be recalled by boosting to reject challenge with tumors expressing influenza A virus antigens. A Schematic illustration of experimental procedure. BALB/c mice (6-8 weeks old) were immunized with $20 \mathrm{HA}$ units of PR8 influenza A virus or mock immunized with PBS. After residing in a pathogen-free facility for 18 months, the PR8-immunized mice were given boosts of PR8 virus $(n=6)$. Ten days later, they were challenged with $10^{6} 4 \mathrm{~T} 1 / \mathrm{Luc}-\mathrm{NP} / \mathrm{HA}$ cells in the mammary fat pad. Age-matched BALB/c mice not immunized with PR8 virus were then challenged with $10^{6} 4 \mathrm{~T} 1 / \mathrm{Luc}$ cells $(n=9)$ or $4 \mathrm{~T} 1 / \mathrm{Luc}-\mathrm{NP} /$ HA cells $(n=9)$ in the mammary fat pad. B The mice in all groups

collectively indicate stronger innate immune responses in PR8-immunized mice than in control mice among the mice implanted with 4T1/Luc-NP/HA cells but not among the mice implanted with 4T1/Luc cells.

With respect to the profiles of the adaptive immune cell repertoire, no significant differences were found in the tumor-draining lymph nodes between PR8-immunized mice and control mice among the mice implanted with 4T1/Luc-NP/HA cells or among the mice implanted with 4T1/Luc cells (data not shown). In the tumors, the percentage of total CD4 $+\mathrm{T}$ cells $\left(\mathrm{CD}^{+} \mathrm{CD}^{+}\right.$; Fig. 4E, left panel) was lower in PR8-immunized mice than in control mice among the mice implanted with 4T1/Luc-NP/HA cells but were monitored for tumor growth using calipers after tumor cell challenge. Tumor volume measurement was discontinued after day 38, when most of the mice challenged with 4T1/Luc cells either had died or had been euthanized. Data are presented as mean \pm standard error of the mean. $* p<0.05$ on days 32 and day 38 for the $4 \mathrm{~T} 1 / \mathrm{Luc}-\mathrm{NP} /$ HA tumors in the aged PR8-immunized mice (with boost) compared to the 4T1/Luc-NP/HA tumors in the age-matched control mice, and for the 4T1/Luc-NP/HA tumors in the aged PR8-immunized mice (with boost) compared with the 4T1/Luc tumors in the age-matched control mice

not among the mice implanted with $4 \mathrm{~T} 1 /$ Luc cells. No differences were observed between PR8-immunized mice and control mice in the percentages of $\mathrm{CD} 4^{+}$effector $\mathrm{T}$ cells $\left(\mathrm{CD} 3{ }^{+} \mathrm{CD}^{+}{ }^{+} \mathrm{CD} 44^{-} \mathrm{CD}^{2} \mathrm{~L}^{-}\right.$; Fig. 4E, middle panel). The percentages of regulatory $\mathrm{T}$ cells $\left(\mathrm{CD}^{+}{ }^{+} \mathrm{CD} 4^{+} \mathrm{FoxP} 3^{+}\right.$; Fig. 4E, right panel) were high and were similar between PR8-immunized mice and control mice implanted with 4T1/Luc cells, consistent with the concept that $4 \mathrm{~T} 1$ tumors are very immunosuppressive [27-30]. Interestingly, the percentage of regulatory $\mathrm{T}$ cells was lower (although not significantly so) in PR8-immunized mice than in control mice implanted with $4 \mathrm{~T} 1 / \mathrm{Luc}-\mathrm{NP} / \mathrm{HA}$ cells; this finding was in agreement with the lower percentage of total 


\section{T1/Luc 4T1/Luc-NP/HA}

A

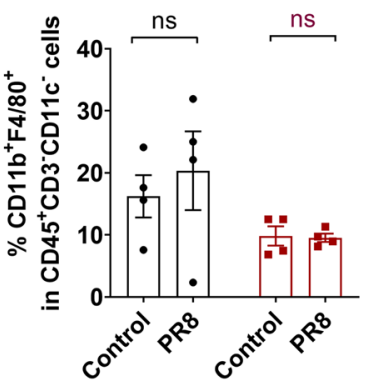

C

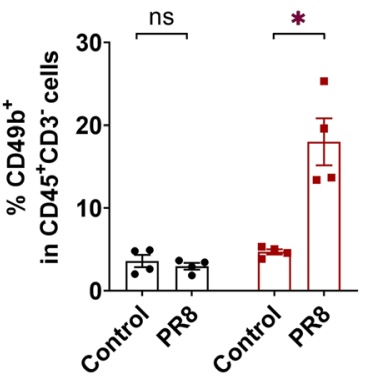

D

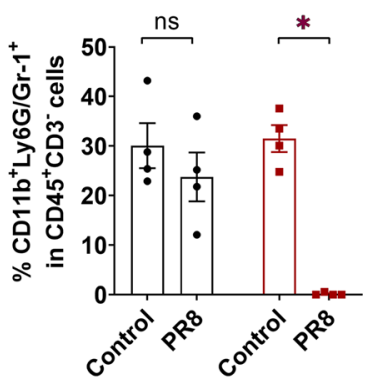

Macrophages

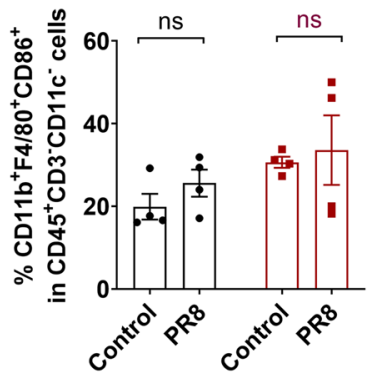

E
B

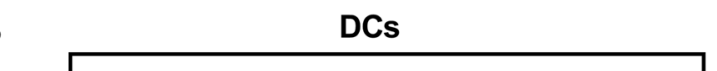

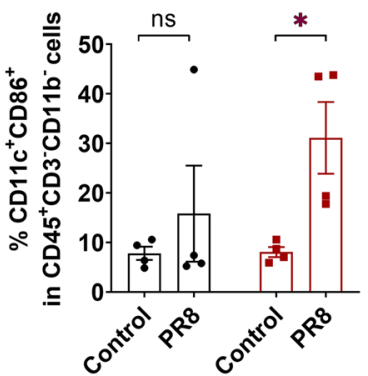

CD4+ T cells

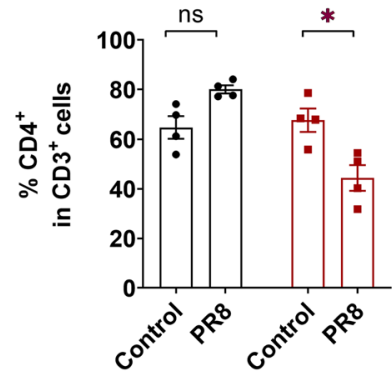

$\mathbf{F}$

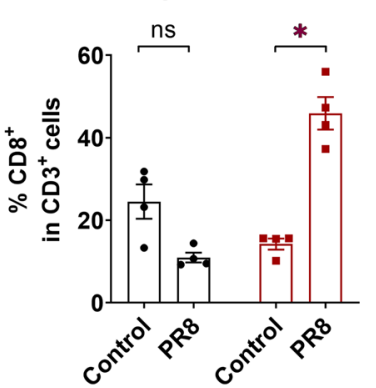

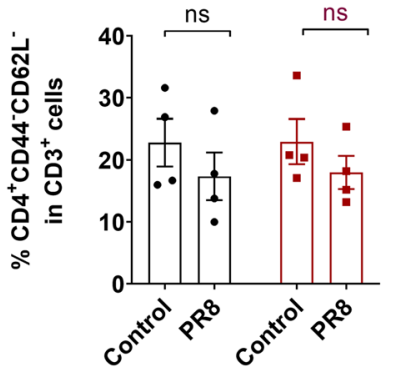

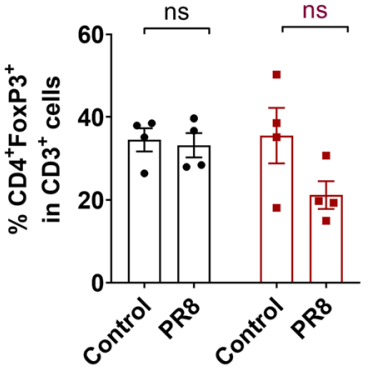

CD8+ T cells
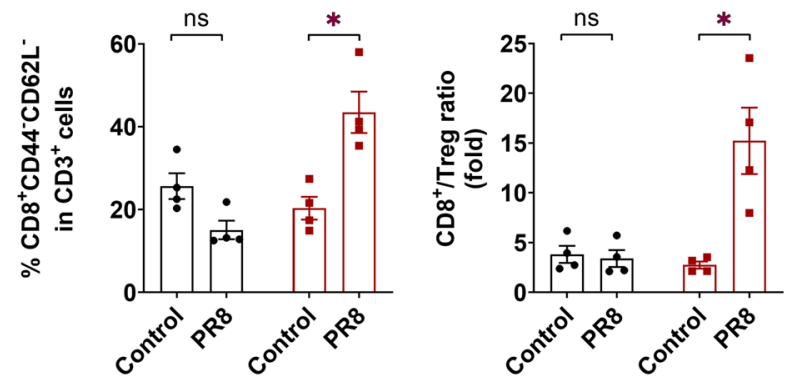

Fig. 4 Both innate and adaptive immune responses to 4T1 mouse mammary tumors expressing influenza A virus antigens are enhanced in PR8-immunized mice compared to control mice. BALB/c mice immunized with PR8 virus or mock immunized with PBS (control) and challenged with $4 \mathrm{~T} 1 / \mathrm{Luc}$ or $4 \mathrm{~T} 1 / \mathrm{Luc}-\mathrm{NP} / \mathrm{HA}$ cells in the mammary fat pad as described in Fig. 2 were euthanized 7 days after tumor cell injection, and tumor samples were collected and processed for analysis of innate and adaptive immune cell markers by multicolor flow cytometry analysis using antibodies against various markers for quantification as shown. A Total tumor-associated macrophages and M1 macrophages. B Total and mature dendritic cells. C NK cells. D Myeloid-derived suppressor cells (MDSC). E Total $\mathrm{CD}^{+}{ }^{+} \mathrm{T}$ cells, $\mathrm{CD}^{+}$effector $\mathrm{T}$ cells, and regulatory $\mathrm{T}$ cells (Tregs). $\mathbf{f}$ Total $\mathrm{CD} 8^{+} \mathrm{T}$ cells, $\mathrm{CD} 8^{+}$effector $\mathrm{T}$ cells, and the ratio of $\mathrm{CD}^{+} \mathrm{T}$ cells to Tregs. * $p<0.05$, ns: not statistically significant

PR8-immunized mice were able to become $\mathrm{CD} 8^{+}$effector $\mathrm{T}$ cells and were then redirected to the tumor sites. This higher percentage of $\mathrm{CD}^{+} \mathrm{T}$ cells led to a higher ratio of $\mathrm{CD}^{+} \mathrm{T}$ cells to regulatory $\mathrm{T}$ cells in PR8-immunized mice than in control mice (Fig. 4F, right panel). Together, these findings indicate stronger adaptive immune responses in PR8-immunized mice than in control mice among the mice 
implanted with 4T1/Luc-NP/HA cells but not among the mice implanted with 4T1/Luc cells.

To sum up, these results from innate and adaptive immune cell profiling corroborate the findings in Fig. 1 through Fig. 3 that preexisting influenza A immunity could be redirected to exert an antitumor activity against syngeneic mouse tumors expressing influenza A-related antigens.

\section{Systemic delivery of influenza A-related peptides encapsulated in tumor-targeting SLNPs to targeted tumors produces an antitumor response in PR8-immunized mice}

Next, to examine whether preexisting influenza A immunity can be harnessed as a novel cancer immunotherapy, we tested if our strategy could be implemented through systemic delivery of MHC-I-compatible influenza A-related peptides to tumors in vivo. We engineered HER2-targeting SLNPs (TZM-MB-SLNPs) loaded with MHC-I-compatible peptides for targeted delivery to EO771 mouse mammary tumor cells transduced for HER2 overexpression (EO771/ HER2). Figure 5 shows detection of chicken ovalbumin (OVA) peptide 257-264 (SIINFEKL), a well-characterized $\mathrm{H}-2 \mathrm{~K}^{\mathrm{b}}$-restricted antigenic peptide [31, 32], by flow cytometry analysis in EO771/HER2 cells implanted in the mammary fat pad in C57BL/6 mice. The SIINFEKL peptide was detected in $\mathrm{H}-2 \mathrm{~K}^{\mathrm{b}}$ in $21.1 \%$ of EO771/HER 2 cells when SIINFEKL was delivered by TZM-MB-SLNPs, compared to only $9.38 \%$ of EO771/HER 2 cells treated with a simple mixture of trastuzumab, SLNPs, and the peptide. These findings indicate that an MHC-I-compatible antigenic peptide could be delivered systemically to targeted tumors for antigen presentation in MHC-I ( $\left.\mathrm{H}-2 \mathrm{~K}^{\mathrm{b}}\right)$.

We then conducted a pilot study to examine the extent to which preexisting influenza A immunity in PR8-immunized mice can be redirected to exert a therapeutic activity following systemic delivery of MHC-I-compatible influenza A-related peptides to targeted tumors. In our pilot study, we found that in C57BL/6 mice implanted with EO771/ HER 2 cells, the tumors started to regress spontaneously $8-9$ days after cell implantation even at $5 \times 10^{6}$ cells/ mouse, which is 100 times the number of parental EO771 cells required to form tumors in C57BL/6 mice. This HER2mediated immune response suppressed the development of EO771/HER2 tumors in C57BL/6 mice over a period of 3-4 weeks after tumor implantation. In contrast, we found that in BALB/c mice implanted with 4T1/Luc-HER2 cells at $2-5 \times 10^{6}$ cells/mouse, tumor size remained stable for 3-4 weeks before tumors finally started to regress. The 4T1/ Luc-HER2 tumor model was therefore chosen to assess the therapeutic effect of systemic delivery of TZM-MB-SLNPs loaded with influenza A-related peptides.

As illustrated in Fig. 6A, prior to implantation of 4T1/ Luc-HER2 cells, one group of BALB/c mice received no treatment, another group of mice received PBS as a mock immunization, and a third group of mice received PR8 virus via nasal dropping followed by a boost using a protocol similar to the one shown in Fig. 2A. Beginning 1 week after tumor cell implantation, the mice in the mock immunization and PR8 immunization groups received 2 doses of TZMMB-SLNPs loaded with two $\mathrm{H}-2 \mathrm{~K}^{\mathrm{d}}$-compatible influenza
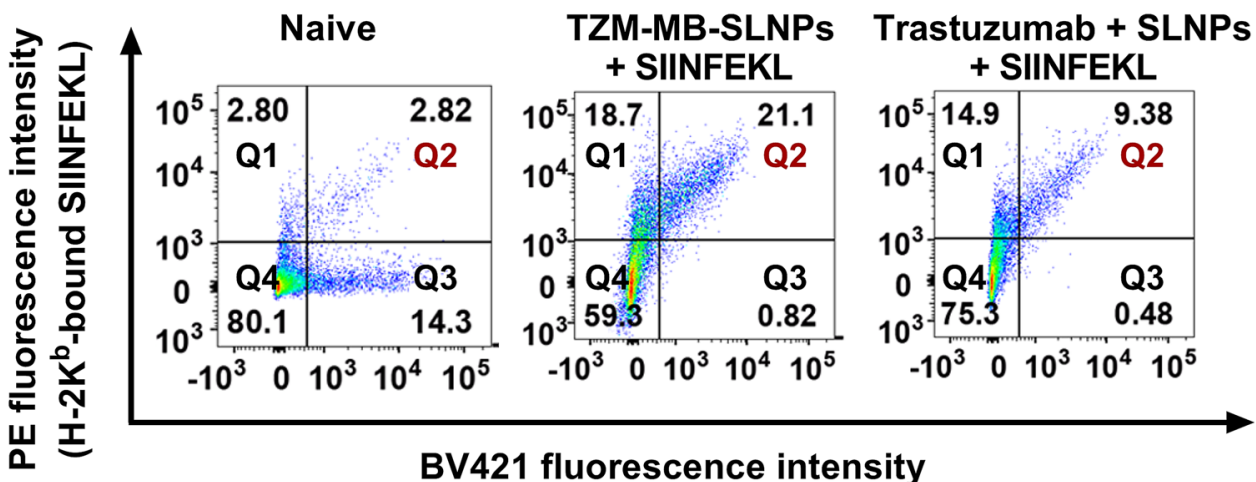

BV421 fluorescence intensity

(HER2)

Fig. 5 MHC-I-compatible peptide delivered by TZM-MB-SLNPs can be presented on targeted mammary tumors in mice. C57BL/6 mice (6-8 weeks old) were implanted with $5 \times 10^{6}$ EO771/HER2 cells in the mammary fat pad. TZM-MB-SLNPs loaded with SIINFEKL peptide were injected via mouse tail vein on day 8 after tumor cell implantation. Mice injected with simple mixture of trastuzumab, SLNPs, and the peptide served as control. The mice were euthanized $24 \mathrm{~h}$ after the injections. The tumors were harvested and processed for flow cytometry analysis after staining with PE-conjugated anti-H$2 \mathrm{~K}^{\mathrm{b}}$-bound OVA257-264 (SIINFEKL) peptide antibody and BV421conjugated anti-HER 2 antibody. The data were analyzed by FlowJo software. The percentages of cells with $\mathrm{H}-2 \mathrm{~K}^{\mathrm{b}}$-bound SIINFEKL in the EO771/HER2 cells from the tumors in each group are shown in Q2 and are representative of the experiment from 3 mice in each group 
A

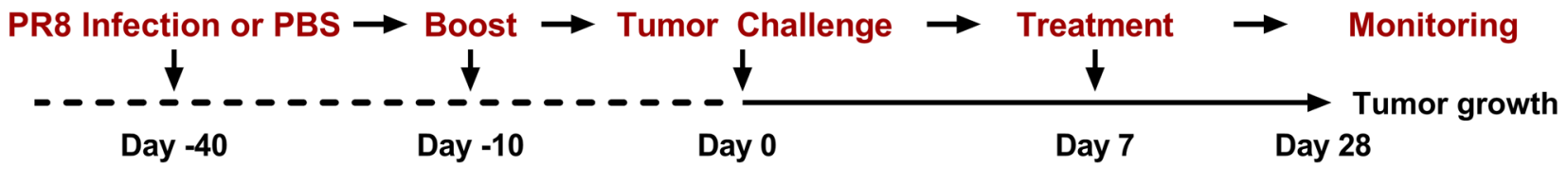

B

Day 7

\section{PBS control mice w/o treatment} (Group A)

\section{PBS control mice w/ treatment} (Group B)

\section{PR8-immunized mice w/ treatment} (Group C)


Day 14
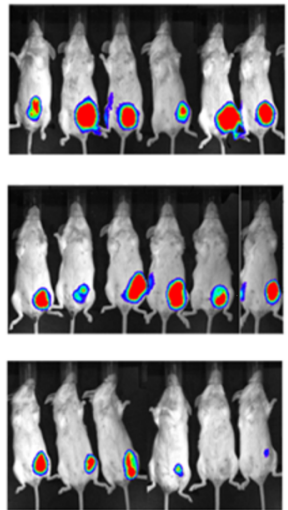

Day 21
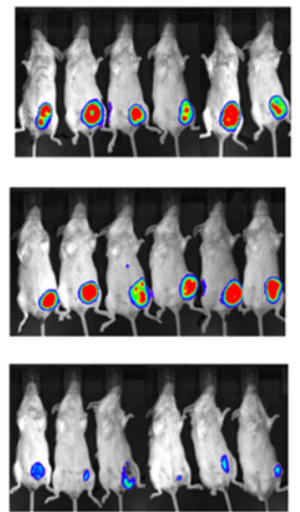

Day 28
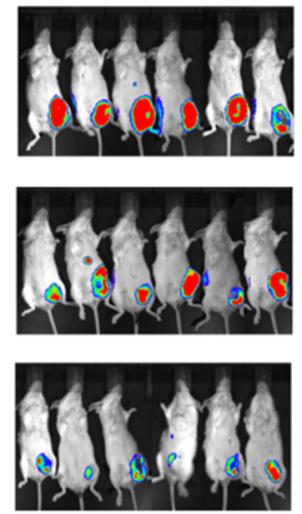
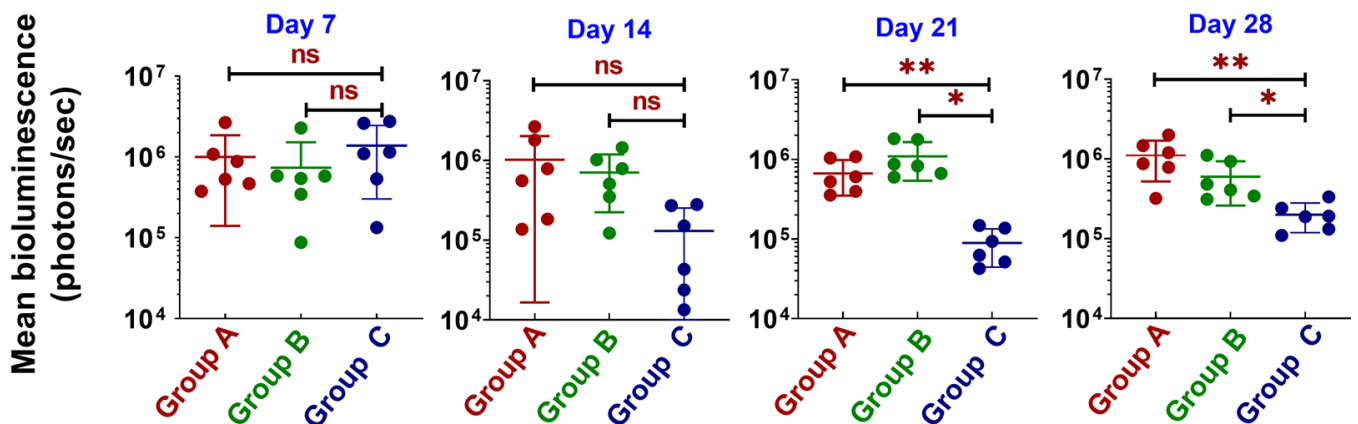

Fig. 6 Preexisting influenza A immunity can be redirected to targeted tumors leading to tumor regression in mice following delivery of MHC-I-compatible influenza A peptides loaded in TZM-MB-SLNPs to the targeted tumors. A Schematic illustration of experimental procedure. BALB/c mice (6-8 weeks old) were mock immunized with PBS (groups A and B) or immunized with 20 HA units of PR8 virus (group C) 40 days before and boosted 10 days before tumor cell challenge, which was followed by treatment and monitoring. B The PR8immunized mice and control mice ( $n=6$ per group) were challenged with $2 \times 10^{6} 4 \mathrm{~T} 1 /$ Luc-HER2 cells in the mammary fat pad on day

A-related peptides, IYSTVASSL (HA-related) and TYQRTRALV (NP-related), by intravenous administration 3 days apart. In the untreated mice, the tumors remained largely static over 28 days as measured by weekly in vivo imaging for tumor bioluminescence as an indicator of tumor burden (Fig. 6B). In the mock-immunized control mice, the tumor burden over 28 days was similar to the tumor burden in the untreated mice. In contrast, in the PR8-immunized mice, the tumor burden was reduced on day 14 and significantly reduced on day 21 and day 28 compared to the tumor burden in the other 2 groups at the same times. When compared to tumor burdens in the PR8-immunized mice on day 21,
0 . Beginning 7 days after tumor challenge, the mice were untreated (group A) or treated with TZM-MB-SLNPs plus the peptides via tail vein injections, twice 3 days apart (groups $B$ and $C$ ). The mice were subjected to monitoring of tumor growth by in vivo imaging system before the treatment on day 7 and weekly after the treatment on days 14,21 , and 28. Mean bioluminescence values of the tumors on days $7,14,21$, and 28 were quantified. The data in log scale are presented by scatter plot (mean $\pm \mathrm{SD}$ ) and compared as shown. $* p<0.05$, ** $p<0.01$, ns: not statistically significant

the tumor burdens on day 28 appeared to re-grow slightly, which may be due to presence of a fraction of tumor cells with inadequate delivery of the peptides, which indicates that additional treatment would be needed. However, after day 28 , tumors in the control group (and also tumors in the other groups) started to regress, indicating that host immune response to HER 2 expressed on 4T1/Luc-HER2 tumors was fully developed. This limitation prevented us from continuing the treatment and conducting an analysis of immune cell phenotype similar to our analysis in the experiment shown in Fig. 4. Nevertheless, these findings provided evidence 
supporting the concept that our strategy could be implemented using a systemic therapy approach.

\section{Discussion}

In this study, we provide preclinical evidence that preexisting influenza A virus immunity can be redirected for treatment of cancer metastasis and we established the feasibility of the approach through systemic delivery of influenza A virus-related MHC-I-compatible peptides to targeted tumors in vivo. These results support our overall strategy of redirecting host preexisting antiviral immunity to cancers for immunotherapy and validate that the strategy could be implemented using a systemic therapy approach.

The idea of harnessing infectious disease-related host immunity for cancer treatment was proposed previously; however, this idea has been tested mainly via local or intratumoral injection of vaccine-related antigens or recombinant viruses, and therapeutic activity has been assessed only in terms of the impact on growth of non-metastatic tumors [9, 12]. In the work reported here, we investigated the antitumor activity of preexisting influenza $\mathrm{A}$ immunity against not only TUBO tumors, non-metastatic syngeneic mammary tumors that grow robustly locally, but also 4T1 tumors, very aggressive and highly metastatic syngeneic mammary tumors that can kill mice. Moreover, we explored for the first time a systemic therapy approach in which influenza A-related MHC-I-compatible peptides encapsulated in tumor-targeting SLNPs engineered to target HER2 were administered intravenously.

HER2, thanks to the introduction of next generation sequencing into clinical practice in the past decade, is emerging as a promising target for genomically informed therapy across a variety of cancer types beyond breast cancer and gastric cancer, the original cancer types in which HER2 was used as a therapeutic target $[33,34]$. However, in our current study, a major limitation of using HER 2 as a representative therapeutic target is that ectopic expression of human HER 2 on syngeneic mouse tumor cells is immunogenic in immunocompetent mice and can cause tumor regression in syngeneic mice. We were able to deal with this limitation in part by implanting a high number of aggressive 4T1/Luc-HER 2 cells for tumor cell challenge. In a 3to 4-week window before host immune response to HER2 was fully launched and curbed tumor growth, we observed a clear therapeutic effect on 4T1/Luc-HER2 tumors following delivery of influenza A NP-related and HA-related peptides in PR8-immunized mice compared to antigen-naïve control mice. We acknowledge that the observed therapeutic effect on 4T1/Luc-HER2 tumors may not be due only to redirection of preexisting influenza A immunity. Possible improvements in the approach for use in our follow-up studies would be to use transgenic mice immunotolerant to human HER2 so that syngeneic mouse tumors overexpressing human HER2 may not be rejected spontaneously [35-37] or to develop a similar SLNP targeting a mouse tumor marker suitable for targeted delivery of MHC-I-compatible antigens.

In the current study, we explored the novel approach of engineering trastuzumab-guided SLNPs (TZM-MB-SLNP) to deliver MHC-compatible peptides to 4T1-Luc/HER2 tumors in mice. We retrieved the sequences of trastuzumab and a membrane-binding domain of membrane-bound $\mathrm{IgG}$ and designed a strategy by fusing the MB domain to the C-terminus of trastuzumab heavy chain through DNA recombination. This fusion of membrane-binding domain, which is hydrophobic, facilitated natural integration of the trastuzumab-MB fusion IgG into the lipid layer of SLNP, generating a novel tumor-targeting SLNP without conventional use of chemical reagents that could damage immunoreactivity of tumor-targeting SLNP [38-40]. Our data clearly show that MHC-I-compatible peptides encapsulated in TZM-MB-SLNPs were successfully presented on MHC-I of the targeted tumors in vivo and that preexisting influenza A immunity in PR8-immunized mice was subsequently redirected to the targeted tumor, exerting a therapeutic antitumor activity.

The current study was designed to obtain proof of our concept by using influenza $\mathrm{A}$ as the viral infection model for redirecting host preexisting immunity to cancer cells. The types of host preexisting immunity that could be harnessed for cancer immunotherapy may be expanded to other viral infections, such as cytomegalovirus infection, which occurs in $50 \%$ to $80 \%$ of adults in the US by age 40 years [41], and to vaccinations that have successfully prevented infectious diseases, such as BCG and trivalent measlesmumps-rubella vaccine. COVID-19 has caused a oncein-a-generation global pandemic, and recent studies show that COVID-19 vaccines induced persistent human germinal center responses and long-lived bone marrow plasma cells in humans $[42,43]$. If upcoming studies confirm that COVID-19 immunity is long-lasting following infection or vaccination, it may be worth testing if COVID-19 immunity could be redirected for cancer immunotherapy using our strategy. With respect to the targets for tumor-specific delivery of viral antigens, candidates other than HER2 that can be considered include epidermal growth factor receptor, which is overexpressed in head and neck cancers and other cancers; folate receptor $\alpha$, which is overexpressed in ovarian cancer and other cancers; and CD19 and CD20, which are overexpressed in B cell lymphoma and lymphocytic leukemia [44]. Last, the SLNP-based delivery system used in current study is approved by the US Food and Drug Administration for testing in clinical trials at MD Anderson Cancer Center (NCT01591356 and NCT01159028). Nevertheless, other nanoparticle platforms should also be explored 
for improvement in efficiency, efficacy and pharmaceutical developability for delivering viral antigens to targeted tumors via systemic administration.

In summary, our findings support the idea that patients' preexisting immunity acquired as a result of natural infection or vaccination could be redirected to tumors as a new type of cancer immunotherapy for treatment of cancer metastasis. Our findings support the feasibility of using a systemic therapy approach for delivery of MHC-I-compatible antigens to targeted tumors to redirect preexisting noncancer immunity to cancer cells.

Acknowledgements This work was supported in part by a grant from the Breast Cancer Research Foundation (BCRF-20-051) and a grant from the Cancer Prevention \& Research Institute of Texas (CPRIT RP200271). The work was also supported in part by the NIH through MD Anderson's Cancer Center Support Grant, 5P30CA016672, which supported the animal and FACS studies performed as part of this study. We thank Stephanie Deming, Research Medical Library, MD Anderson Cancer Center, for editing this manuscript.

Author contributions BKRC, SQ, YL, and BO performed the experiments and analyzed data. BKRC and ZF conceived the concept and designed the project. GL and BO contributed to project design. BKRC and $\mathrm{ZF}$ wrote the manuscript, and all authors approved this version. ZF supervised the overall project.

\section{Declarations}

Conflict of interest The authors report no conflict of interest.

\section{References}

1. Greenwood B (2014) The contribution of vaccination to global health: past, present and future. Philos Trans R Soc Lond B Biol Sci 369:20130433. https://doi.org/10.1098/rstb.2013.0433

2. Butterfield LH (2015) Cancer vaccines. BMJ 350:h988. https:// doi.org/10.1136/bmj.h988

3. Mullard A (2017) New cancer vaccines show clinical promise. Nat Rev Drug Discov 16:519. https://doi.org/10.1038/nrd.2017.150

4. Cohen PA, Jhingran A, Oaknin A, Denny L (2019) Cervical cancer. Lancet 393:169-182. https://doi.org/10.1016/S0140-6736(18) 32470-X

5. Lawrence MS, Stojanov P, Polak P, Kryukov GV, Cibulskis K, Sivachenko A, Carter SL, Stewart C, Mermel CH, Roberts SA, Kiezun A, Hammerman PS, McKenna A, Drier Y, Zou L, Ramos AH, Pugh TJ, Stransky N, Helman E, Kim J, Sougnez C, Ambrogio L, Nickerson E, Shefler E, Cortes ML, Auclair D, Saksena G, Voet D, Noble M, DiCara D, Lin P, Lichtenstein L, Heiman DI, Fennell T, Imielinski M, Hernandez B, Hodis E, Baca S, Dulak AM, Lohr J, Landau DA, Wu CJ, Melendez-Zajgla J, HidalgoMiranda A, Koren A, McCarroll SA, Mora J, Lee RS, Crompton B, Onofrio R, Parkin M, Winckler W, Ardlie K, Gabriel SB, Roberts CW, Biegel JA, Stegmaier K, Bass AJ, Garraway LA, Meyerson M, Golub TR, Gordenin DA, Sunyaev S, Lander ES, Getz G (2013) Mutational heterogeneity in cancer and the search for new cancer-associated genes. Nature 499:214-218. https://doi. org/10.1038/nature 12213

6. Murciano-Goroff YR, Warner AB, Wolchok JD (2020) The future of cancer immunotherapy: microenvironment-targeting combinations. Cell Res 30:507-519. https://doi.org/10.1038/ s41422-020-0337-2

7. Emens LA, Ascierto PA, Darcy PK, Demaria S, Eggermont AMM, Redmond WL, Seliger B, Marincola FM (2017) Cancer immunotherapy: Opportunities and challenges in the rapidly evolving clinical landscape. Eur J Cancer 81:116-129. https:// doi.org/10.1016/j.ejca.2017.01.035

8. Baitsch L, Baumgaertner P, Devevre E, Raghav SK, Legat A, Barba L, Wieckowski S, Bouzourene H, Deplancke B, Romero P, Rufer N, Speiser DE (2011) Exhaustion of tumor-specific CD8(+) T cells in metastases from melanoma patients. J Clin Invest 121:2350-2360. https://doi.org/10.1172/JCI46102

9. Biot C, Rentsch CA, Gsponer JR, Birkhauser FD, JusforguesSaklani H, Lemaitre F, Auriau C, Bachmann A, Bousso P, Demangel C, Peduto L, Thalmann GN, Albert ML (2012) Preexisting BCG-specific T cells improve intravesical immunotherapy for bladder cancer. Sci Transl Med. https://doi.org/10.1126/scitr anslmed.3003586

10. Morales A, Eidinger D, Bruce AW (1976) Intracavitary bacillus calmette-guerin in the treatment of superficial bladder tumors. J Urol 116:180-183. https://doi.org/10.1016/s0022-5347(17) 58737-6

11. Coley WB (1891) II. Contribution to the knowledge of sarcoma. Ann Surg 14:199-220. https://doi.org/10.1097/00000658-18911 2000-00015

12. Hu W, Davis JJ, Zhu H, Dong F, Guo W, Ang J, Peng H, Guo ZS, Bartlett DL, Swisher SG, Fang B (2007) Redirecting adaptive immunity against foreign antigens to tumors for cancer therapy. Cancer Biol Ther 6:1773-1779. https://doi.org/10. 4161/cbt.6.11.4855

13. Newman JH, Chesson CB, Herzog NL, Bommareddy PK, Aspromonte SM, Pepe R, Estupinian R, Aboelatta MM, Buddhadev S, Tarabichi S, Lee M, Li S, Medina DJ, Giurini EF, Gupta KH, Guevara-Aleman G, Rossi M, Nowicki C, Abed A, Goldufsky JW, Broucek JR, Redondo RE, Rotter D, Jhawar SR, Wang SJ, Kohlhapp FJ, Kaufman HL, Thomas PG, Gupta V, Kuzel TM, Reiser J, Paras J, Kane MP, Singer EA, Malhotra J, Denzin LK, Sant'Angelo DB, Rabson AB, Lee LY, Lasfar A, Langenfeld J, Schenkel JM, Fidler MJ, Ruiz ES, Marzo AL, Rudra JS, Silk AW, Zloza A (2020) Intratumoral injection of the seasonal flu shot converts immunologically cold tumors to hot and serves as an immunotherapy for cancer. Proc Natl Acad Sci U S A 117:1119-1128. https://doi.org/10.1073/pnas.19040 22116

14. Rosato PC, Wijeyesinghe S, Stolley JM, Nelson CE, Davis RL, Manlove LS, Pennell CA, Blazar BR, Chen CC, Geller MA, Vezys V, Masopust D (2019) Virus-specific memory T cells populate tumors and can be repurposed for tumor immunotherapy. Nat Commun 10:567. https://doi.org/10.1038/s41467-019-08534-1

15. Zhu W, Wang C, Wang BZ (2017) From variation of influenza viral proteins to vaccine development. Int J Mol Sci 18:1554. https://doi.org/10.3390/ijms18071554

16. Tchilian E, Holzer B (2017) Harnessing local immunity for an effective universal swine influenza vaccine. Viruses 9:v9050098. https://doi.org/10.3390/v9050098

17. Rovero S, Amici A, Di CE, Bei R, Nanni P, Quaglino E, Porcedda P, Boggio K, Smorlesi A, Lollini PL, Landuzzi L, Colombo MP, Giovarelli M, Musiani P, Forni G (2000) DNA vaccination against rat her-2/Neu p185 more effectively inhibits carcinogenesis than transplantable carcinomas in transgenic BALB/c mice. J Immunol 165:5133-5142. https://doi.org/10.4049/jimmunol.165.9.5133

18. Curcio C, Di CE, Clynes R, Smyth MJ, Boggio K, Quaglino E, Spadaro M, Colombo MP, Amici A, Lollini PL, Musiani P, Forni G (2003) Nonredundant roles of antibody, cytokines, and perforin in the eradication of established Her-2/neu carcinomas. J Clin Invest 111:1161-1170. https://doi.org/10.1172/JCI17426 
19. Yewdell JW, Bennink JR, Smith GL, Moss B (1985) Influenza A virus nucleoprotein is a major target antigen for cross-reactive anti-influenza A virus cytotoxic T lymphocytes. Proc Natl Acad Sci U S A 82:1785-1789. https://doi.org/10.1073/pnas.82.6.1785

20. Caton AJ, Brownlee GG, Yewdell JW, Gerhard W (1982) The antigenic structure of the influenza virus $\mathrm{A} / \mathrm{PR} / 8 / 34$ hemagglutinin (H1 subtype). Cell 31:417-427. https://doi.org/10.1016/00928674(82)90135-0

21. Liu STH, Behzadi MA, Sun W, Freyn AW, Liu WC, Broecker F, Albrecht RA, Bouvier NM, Simon V, Nachbagauer R, Krammer F, Palese P (2018) Antigenic sites in influenza H1 hemagglutinin display species-specific immunodominance. J Clin Invest 128:4992-4996. https://doi.org/10.1172/JCI122895

22. Gerber P, Loosli CG, Hambre D (1955) Antigenic variants of influenza A virus, PR8 strain. I. Their development during serial passage in the lungs of partially immune mice. J Exp Med 101:627-638. https://doi.org/10.1084/jem.101.6.627

23. Gerber P, Loosli CG, Hambre D (1956) Antigenic variants of influenza A virus (PR8 strain). II. Serological and immunological characteristics of variants derived from variants. J Exp Med 103:413-424. https://doi.org/10.1084/jem.103.4.413

24. Bayraktar R, Ivan C, Bayraktar E, Kanlikilicer P, Kabil NN, Kahraman N, Mokhlis HA, Karakas D, Rodriguez-Aguayo C, Arslan A, Sheng J, Wong S, Lopez-Berestein G, Calin GA, Ozpolat B (2018) Dual suppressive effect of miR-34a on the FOXM1/eEF2kinase axis regulates triple-negative breast cancer growth and invasion. Clin Cancer Res 24:4225-4241. https://doi.org/10.1158/ 1078-0432.CCR-17-1959

25. Shao L, Kahraman N, Yan G, Wang J, Ozpolat B, Ittmann M (2020) Targeting the TMPRSS2/ERG fusion mRNA using liposomal nanovectors enhances docetaxel treatment in prostate cancer. Prostate 80:65-73. https://doi.org/10.1002/pros.23918

26. Pulaski BA, Ostrand-Rosenberg S (2001) Mouse 4T1 breast tumor model. Curr Protoc Immunol. https://doi.org/10.1002/04711 42735.im2002s39

27. Dexter DL, Kowalski HM, Blazar BA, Fligiel Z, Vogel R, Heppner GH (1978) Heterogeneity of tumor cells from a single mouse mammary tumor. Cancer Res 38:3174-3181

28. Pulaski BA, Ostrand-Rosenberg S (1998) Reduction of established spontaneous mammary carcinoma metastases following immunotherapy with major histocompatibility complex class II and B7.1 cell-based tumor vaccines. Cancer Res 58:1486-1493

29. Chen L, Huang TG, Meseck M, Mandeli J, Fallon J, Woo SL (2007) Rejection of metastatic 4T1 breast cancer by attenuation of Treg cells in combination with immune stimulation. Mol Ther 15:2194-2202. https://doi.org/10.1038/sj.mt.6300310

30. Kim K, Skora AD, Li Z, Liu Q, Tam AJ, Blosser RL, Diaz LA Jr, Papadopoulos N, Kinzler KW, Vogelstein B, Zhou S (2014) Eradication of metastatic mouse cancers resistant to immune checkpoint blockade by suppression of myeloid-derived cells. Proc Natl Acad Sci U S A 111:11774-11779. https://doi.org/10.1073/pnas.14106 26111

31. Rotzschke O, Falk K, Stevanovic S, Jung G, Walden P, Rammensee HG (1991) Exact prediction of a natural T cell epitope. Eur J Immunol 21:2891-2894. https://doi.org/10.1002/eji.1830211136

32. Lipford GB, Hoffman M, Wagner H, Heeg K (1993) Primary in vivo responses to ovalbumin. Probing the predictive value of the Kb binding motif. J Immunol 150:1212-1222

33. Meric-Bernstam F, Hurwitz H, Raghav KPS, McWilliams RR, Fakih M, VanderWalde A, Swanton C, Kurzrock R, Burris H, Sweeney C, Bose R, Spigel DR, Beattie MS, Blotner S, Stone A, Schulze K, Cuchelkar V, Hainsworth J (2019) Pertuzumab plus trastuzumab for HER2-amplified metastatic colorectal cancer (MyPathway): an updated report from a multicentre, open-label, phase 2a, multiple basket study. Lancet Oncol 20:518-530. https:// doi.org/10.1016/S1470-2045(18)30904-5

34. Oh DY, Bang YJ (2020) HER2-targeted therapies - a role beyond breast cancer. Nat Rev Clin Oncol 17:33-48. https://doi.org/10. 1038/s41571-019-0268-3

35. Wang S, Astsaturov IA, Bingham CA, Mccarthy KM, von Mehren M, Xu W, Alpaugh RK, Tang Y, Littlefield BA, Hawkins LD, Ishizaka ST, Weiner LM (2012) Effective antibody therapy induces host-protective antitumor immunity that is augmented by TLR 4 agonist treatment. Cancer Immunol Immunother 61:49-61. https://doi.org/10.1007/s00262-011-1090-7

36. Surana R, Wang S, Xu W, Jablonski SA, Weiner LM (2014) IL4 limits the efficacy of tumor-targeted antibody therapy in a murine model. Cancer Immunol Res 2:1103-1112. https://doi.org/10. 1158/2326-6066.CIR-14-0103

37. Chaganty BKR, Qiu S, Gest A, Lu Y, Ivan C, Calin GA, Weiner LM, Fan Z (2018) Trastuzumab upregulates PD-L1 as a potential mechanism of trastuzumab resistance through engagement of immune effector cells and stimulation of IFNgamma secretion. Cancer Lett 430:47-56. https://doi.org/10.1016/j.canlet.2018.05. 009

38. Bendas G (2001) Immunoliposomes: a promising approach to targeting cancer therapy. BioDrugs 15:215-224. https://doi.org/ 10.2165/00063030-200115040-00002

39. Park JW, Benz CC, Martin FJ (2004) Future directions of liposome- and immunoliposome-based cancer therapeutics. Semin Oncol 31:196-205. https://doi.org/10.1053/j.seminoncol.2004. 08.009

40. Manjappa AS, Chaudhari KR, Venkataraju MP, Dantuluri P, Nanda B, Sidda C, Sawant KK, Murthy RS (2011) Antibody derivatization and conjugation strategies: application in preparation of stealth immunoliposome to target chemotherapeutics to tumor. J Control Release 150:2-22. https://doi.org/10.1016/j.jconrel.2010. 11.002

41. Cannon MJ, Schmid DS, Hyde TB (2010) Review of cytomegalovirus seroprevalence and demographic characteristics associated with infection. Rev Med Virol 20:202-213. https://doi.org/10. 1002/rmv. 655

42. Turner JS, Kim W, Kalaidina E, Goss CW, Rauseo AM, Schmitz AJ, Hansen L, Haile A, Klebert MK, Pusic I, O'Halloran JA, Presti RM, Ellebedy AH (2021) SARS-CoV-2 infection induces long-lived bone marrow plasma cells in humans. Nature 595:421425. https://doi.org/10.1038/s41586-021-03647-4

43. Turner JS, O'Halloran JA, Kalaidina E, Kim W, Schmitz AJ, Zhou JQ, Lei T, Thapa M, Chen RE, Case JB, Amanat F, Rauseo AM, Haile A, Xie X, Klebert MK, Suessen T, Middleton WD, Shi PY, Krammer F, Teefey SA, Diamond MS, Presti RM, Ellebedy AH (2021) SARS-CoV-2 mRNA vaccines induce persistent human germinal centre responses. Nature 596:109-113. https://doi.org/ 10.1038/s41586-021-03738-2

44. Zahavi D, Weiner L (2020) Monoclonal antibodies in cancer therapy. Antibodies (Basel) 9:34. https://doi.org/10.3390/antib90300 34

Publisher's Note Springer Nature remains neutral with regard to jurisdictional claims in published maps and institutional affiliations. 